\title{
In Vivo Evidence for NMDA Receptor-Mediated Excitotoxicity in a Murine Genetic Model of Huntington Disease
}

\author{
Mary Y. Heng, ${ }^{1,2}$ Peter J. Detloff, ${ }^{3}$ Phillip L. Wang, ${ }^{4}$ Joe Z. Tsien, ${ }^{4}$ and Roger L. Albin ${ }^{1,2,5}$ \\ ${ }^{1}$ Neuroscience Graduate Program and ${ }^{2}$ Department of Neurology, University of Michigan, Ann Arbor, Michigan 48109, ${ }^{3}$ Department of Biochemistry and \\ Molecular Genetics, University of Alabama at Birmingham, Birmingham, Alabama 36294, ${ }^{4}$ Brain Discovery Institute, Medical College of Georgia, Augusta, \\ Georgia 30912, and ${ }^{5}$ Geriatrics Research, Education, and Clinical Center, Veterans Affairs Ann Arbor Health System, Ann Arbor, Michigan 48105
}

$\mathrm{N}$-methyl-D-aspartate receptor (NMDAR)-mediated excitotoxicity is implicated as a proximate cause of neurodegeneration in Huntington Disease (HD). This hypothesis has not been tested rigorously in vivo. NMDAR-NR2B subunits are a major NR2 subunit expressed by striatal medium spiny neurons that degenerate in HD. To test the excitotoxic hypothesis, we crossed a well validated murine genetic model of $\mathrm{HD}\left(\mathrm{Hdh}{ }^{(\mathrm{CAG}) 150}\right.$ ) with a transgenic line overexpressing NMDAR-NR2B subunits. In the resulting double-mutant line, we show exacerbation of selective striatal neuron degeneration. This is the first direct in vivo evidence of NR2B-NMDAR-mediated excitotoxicity in the context of HD. Our results are consistent with previous suggestions that direct and/or indirect interactions of mutant huntingtin with NMDARs are a proximate cause of neurodegeneration in HD.

\section{Introduction}

Huntington disease (HD) is a dominantly inherited, incurable neurodegeneration caused by expanded CAG repeat/polyglutamine repeats within the huntingtin locus, resulting in a pathogenic huntingtin protein (htt). Degeneration of striatal medium spiny neurons (MSNs) is a hallmark of HD. Clinical manifestations include progressive cognitive decline, psychiatric disturbances, and involuntary movements. Although the molecular mechanisms underlying selective degeneration of MSNs in HD are not understood, convergent evidence supports a role for $\mathrm{N}$-methyl-D-aspartate receptor (NMDAR)-mediated excitotoxicity (Coyle and Schwarcz, 1976; McGeer and McGeer, 1976; Schwarcz et al., 1983; Beal et al., 1986; Fan et al., 2007).

The striatum receives dense glutamatergic corticostriatal and thalamostriatal inputs, and MSNs are endowed heavily with glutamate receptors, including NMDARs. Coyle and Schwarcz (1976) and McGeer and McGeer (1976) developed the first models of HD by demonstrating that acute intrastriatal administration of the glutamate agonist kainic acid produced neurodegeneration with features of HD. Later work indicated that acute striatal lesions with NMDAR-selective agonists reproduced more features of HD striatal pathology (Beal et al., 1986; Bazzett et al.,

Received Nov. 22, 2008; revised Jan. 29, 2009; accepted Feb. 8, 2009.

This work was supported by a Veterans Affairs Merit Review grant and the Huntington Disease Society of America. We acknowledge Lauren Cline, Kevin Duong, Chad Green, Erin Katz, Alex Martusiewicz, Adam Myrold, and Rebecca York for their technical assistance. We thank Dr. Tom Morrow for use of his MCID system and Dr. Kirk Frey for use of his stereology apparatus. We thank the anonymous reviewers for careful evaluation of a previous version of this manuscript and several constructive criticisms.

Correspondence should be addressed to Dr. Roger L. Albin, 5023 Biomedical Science Research Building, University of Michigan, 109 Zina Pitcher Place, Ann Arbor, MI 48109-2200.E-mail: ralbin@umich.edu.

DOI:10.1523/JNEUROSCI.5599-08.2009

Copyright $\odot 2009$ Society for Neuroscience $\quad$ 0270-6474/09/293200-06\$15.00/0
1993; Ferrante et al., 1993). This is true for both NMDAR agonists and metabolic inhibitors whose indirect effects facilitate NMDAR activation (Brouillet et al., 1995; Greene and Greenamyre, 1995). Although the correlation between the effects of acutely administered NMDAR agonists and HD striatal pathology is impressive, the NMDAR excitotoxicity hypothesis of striatal degeneration in HD has not been previously tested rigorously in vivo.

NMDARs are hetero-multimeric ionotropic receptors that mediate extracellular calcium entry and consist of NR1 subunits and NR2 (A-D) or NR3 (A-C) subunits (Dingledine et al., 1999; Waxman and Lynch, 2005). Pharmacological and functional properties of NMDARs depend heavily on NR2 subunit composition (Cull-Candy et al., 2001; Loftis and Janowsky, 2003). NMDAR activation promotes both prodeath and prosurvival signaling (Papadia and Hardingham, 2007). Regulation of the balance between prodeath and prosurvival NMDAR signaling is understood incompletely. In some model systems, extrasynaptic NMDARs promote prodeath signals, whereas synaptic NMDARs promote neuronal survival (Hardingham et al., 2002; Léveillé et al., 2008; Papadia et al., 2008; Martel et al., 2009). Other data suggests that the critical factor is NMDAR subunit composition: NR2B-containing NMDARs promoting neuronal death and NR2A-containing NMDARs promoting neuronal survival (Liu et al., 2007). These hypotheses may be partially convergent. In maturer mammalian CNS synapses, NR2B-containing NMDARs tend to be extrasynaptic, whereas NR2A-containing NMDARs dominate synapses (Tovar and Westbrook, 1999). NR2B subunit containing NMDARs are highly expressed by MSNs (Monyer et al., 1992). Previous in vitro studies suggest sensitization of NR2B function by mutant htt (Chen et al., 1999; Zeron et al., 2001).

To determine whether striatal pathology and behavioral defi- 
cits of HD are caused by NMDAR-mediated excitotoxic injury in vivo, we created a modified murine model of excitotoxic injury by crossing a well validated murine genetic model of $\mathrm{HD}$,

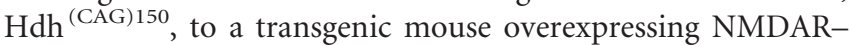
NR2B subunits (Tang et al., 1999; Heng et al., 2007).

\section{Materials and Methods}

Hdh150/+;NR2BTg/WT double-mutant mice. Interbreeding the $\mathrm{Hdh}^{(\mathrm{CAG}) 150}$ and NR2B transgenic lines results in four groups of mice, $\mathrm{Hdh}+/+; \mathrm{NR} 2 \mathrm{~B}^{\mathrm{WT} / \mathrm{WT}}$ [wild-type (WT) huntingtin; no transgene], $\mathrm{Hdh}+/+; \mathrm{NR} 2 \mathrm{~B}^{\mathrm{Tg} / \mathrm{WT}}$ (wild-type huntingtin; one NR2B transgene copy), Hdh150/+; NR2B WT/WT (one mutant huntingtin copy; no transgene), Hdh150/+; NR2B ${ }^{\text {Tg/WT }}$ (one mutant huntingtin copy; one NR2B transgene copy).

All four groups were generated from a cross of $\mathrm{Hdh}{ }^{(\mathrm{CAG}) 150}$ mice maintained on a mixed genetic background, 129/Ola and C57BL/J6 expressing 75-90\% C57BL/6; (P. J. Detloff, unpublished data), with NR2B transgenic mice maintained on a genetic $\mathrm{CBA} / \mathrm{C} 57 \mathrm{BL} / 6 \mathrm{~F} 1$ hybrid background resulting in an F1 mixed background 129/Ola and CBA/C57BL/ J6. Both male and female mice and WT littermates were used. All animals were housed in cages grouped by gender with food and water ad libitum. Animals were housed in specific pathogen-free conditions with a $12 \mathrm{~h}$ light/dark cycle maintained at $23^{\circ} \mathrm{C}$. All procedures were conducted in compliance with the Guide for the Care and Use of Laboratory Animals and approved by the Committee on Use and Care of Animals (UCUCA), University of Michigan, and the Veterinary Medical Unit (VMU) at the Veterans Affairs Ann Arbor Health System.

Genotyping. All mice studied were genotyped for both Hdh alleles and the NR2B transgene. The Hdh allele and NR2B transgene genotyping protocols are published (Tang et al., 1999; Heng et al., 2007). Periodic CAG sizing was performed outside our laboratory (Laragen, Los Angeles, CA) to confirm consistency of CAG repeat number, which ranged from 145 to 150 CAG repeats. For zygosity testing, NR2B transgene detection was performed outside our laboratory (Charles River Laboratories).

Euthanasia. Animals were killed according to national guidelines. Euthanasia was performed by decapitation and approved by UCUCA and the VMU.

Western blotting. Brains from Hdh150/+;NR2B ${ }^{\mathrm{Tg} / \mathrm{WT}}$ and Hdh150/ $+; \mathrm{NR} 2 \mathrm{~B}^{\mathrm{WT} / \mathrm{WT}}$ were flash-frozen. Striata were homogenized in radioimmunoprecipitation assay buffer containing proteinase inhibitor mixture (Roche) and total protein extracts were obtained. Protein concentration was determined by the Bradford Assay (Bio-Rad). Approximately $60 \mu \mathrm{g}$ was separated by SDS-PAGE (4-12\% gradient) and transferred to nitrocellulose membranes. Membranes were blocked in 5\% nonfat milk in PBS with $0.1 \%$ Tween for $1 \mathrm{~h}$ at room temperature and probed overnight at $4^{\circ} \mathrm{C}$ with antibodies raised against NR2B $(1: 1000)$ or Actin $(1: 500)$ (Sigma-Aldrich), washed in PBS containing 0.1\% Tween, and incubated with secondary antibodies in 5\% nonfat milk in PBS with $0.1 \%$ Tween for $1 \mathrm{~h}$. Membranes were washed in PBS containing $0.1 \%$ Tween followed by several washes in PBS, and protein bands were visualized by chemiluminescence (Pierce) and autoradiography.

Behavioral examination. Six behavioral assays were used: (1) accelerating rotarod, (2) hanging wire test, (3) tail suspension test, (4) activity monitoring, (5) footprint analysis, and (6) balance beam. All tests were performed at 20,40, 50, 70, and 100 weeks (Heng et al., 2007). Eight to fourteen animals were used per group.

Pathologic analyses. Immunohistochemistry, stereology, and receptor autoradiography analyses were performed as described previously (Heng et al., 2007).

Stereological counts of striatal neurons were obtained from striata of animals at 70 and 100 weeks of age using StereoInvestigator software (Microbrightfield). The optical fractionator method was used to generate an estimate of NeuN immunoreactive cells. Striatal volume was reconstructed with StereoInvestigator software. Serially cut sagittal tissue sections (every fourth section) were analyzed for one entire hemisphere of animals in each genotype cohort ( $n=4$ per group).

Statistical analyses. All studies were performed blind to genotype. Comparisons were performed with one-way ANOVA and post hoc com- parisons with the Tukey honestly significant difference when $p<0.05$. Repeated measures ANOVA was performed for behavioral tests requiring repeated tests. A critical $p<0.05$ was used for statistical significance in all analyses. SPSS was used.

\section{Results}

\section{NR2B expression}

Western blot analysis confirmed that Hdh150/+;NR2B ${ }^{\text {Tg/WT }}$ double-mutant mice exhibited increased levels of NR2BNMDAR subunits compared with Hdh150/+;NR2B WT/WT littermate controls (supplemental Fig. S1, available at www. jneurosci.org as supplemental material).

\section{Hdh150/+;NR2 B ${ }^{\mathrm{Tg} / \mathrm{WT}}$ double-mutant mice exhibit striatal neuron loss and decreased striatal dopamine receptors} At 100 weeks of age, $\mathrm{Hdh} 150 /+; \mathrm{NR} 2 \mathrm{~B}^{\mathrm{Tg} / \mathrm{WT}}$ double-mutant mice displayed atrophic and irregularly shaped striatal neurons compared with controls $\left(\mathrm{Hdh}+/+; \mathrm{NR} 2 \mathrm{~B}^{\mathrm{WT} / \mathrm{WT}}, \mathrm{Hdh}+/\right.$ $+; \mathrm{NR} 2 \mathrm{~B}^{\mathrm{Tg} / \mathrm{WT}}$ and Hdh150/+;NR2B ${ }^{\mathrm{WT} / \mathrm{WT}}$ ) (Fig. 1 $\left.1 a-d\right)$. The Hdh150/+;NR2B ${ }^{\mathrm{Tg} / \mathrm{WT}}$ double mutants exhibited marked decreases in striatal neuron number and striatal volume with a mean $51 \%$ decrease in striatal neuron number and a mean $36 \%$ decrease in striatal volume compared with all three control groups $\left(\mathrm{Hdh}+/+; \mathrm{NR} 2 \mathrm{~B}^{\mathrm{WT} / \mathrm{WT}}, \mathrm{Hdh}+/+; \mathrm{NR} 2 \mathrm{~B}^{\mathrm{Tg} / \mathrm{WT}}\right.$ and Hdh150/+;NR2B ${ }^{\text {WT/WT }}$ ) (Fig. 1e,f). At 70 weeks, there was no decrease in striatal neuron number or volume (data not shown).

Striatal pathology observed in double-mutant mice was confirmed by loss of striatal dopamine $\mathrm{D}_{1}$ and $\mathrm{D}_{2}$ receptors (Fig. 2; supplemental Table 1, available at www.jneurosci.org as supplemental material). The Hdh150/+;NR2B ${ }^{\text {Tg/WT }}$ double-mutant mice showed $\sim 45 \%$ decreases of $\mathrm{D}_{1}$ receptor binding in the ventral and dorsal striatum compared with both $\mathrm{Hdh}+/$ + ;NR2B ${ }^{\mathrm{WT} / \mathrm{WT}}$ and $\mathrm{Hdh}+/+; \mathrm{NR} 2 \mathrm{~B}^{\mathrm{Tg} / \mathrm{WT}}$ wild-type mice (Fig. 2a). Although not significantly different, Hdh150/ + ;NR2B ${ }^{\mathrm{WT} / \mathrm{WT}}$ mice exhibit a decrease of $\mathrm{D}_{1}$ receptor binding intermediate between the $\mathrm{Hdh}+/+; \mathrm{NR} 2 \mathrm{~B}^{\mathrm{WT} / \mathrm{WT}}, \mathrm{Hdh}+/$ $+; \mathrm{NR} 2 \mathrm{~B}^{\mathrm{Tg} / \mathrm{WT}}$ wild-type controls and Hdh150/+;NR2B $\mathrm{B}^{\mathrm{Tg} / \mathrm{WT}}$ double-mutant mice. Hdh150/+;NR2B ${ }^{\mathrm{Tg} / \mathrm{WT}}$ double mutants exhibited an $\sim 50 \%$ reduction in the ventral and dorsal striatal $\mathrm{D}_{2}$ receptor binding compared with $\mathrm{Hdh}+/+; \mathrm{NR} 2 \mathrm{~B}^{\mathrm{WT} / \mathrm{WT}}$ wildtype controls. Hdh150/+;NR2B ${ }^{\text {WT/WT }}$ again displayed an intermediate effect (Fig. 2b). GABA $\mathrm{A}$ /benzodiazepine receptor binding was used to survey multiple extrastriatal brain regions and revealed no differences between groups at 100 weeks, indicating little or no neuronal loss in these brain regions (Fig. 2c). Decreased $D_{1}$ and $D_{2}$ receptor binding was observed in double mutants at 70 weeks (Fig. 2d,e). The Hdh150/+;NR2B ${ }^{\text {Tg/WT }}$ doublemutant mice and Hdh150/+;NR2B ${ }^{\text {WT/WT }}$ mice displayed similar average reductions in $\mathrm{D}_{1}$ - and $\mathrm{D}_{2}$-binding sites in both dorsal and ventral striatum. Both $\mathrm{D}_{1}$ - and $\mathrm{D}_{2}$-binding decreases approximated 30\% (Fig. 2d,e).

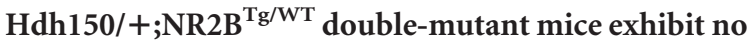 change in distribution of neuronal intranuclear inclusions} We determined the distribution of htt aggregates. Neuronal intranuclear inclusions (NIIs) saturated striatal neurons in doublemutant and Hdh150/+;NR2B ${ }^{\text {WT/WT }}$ mice at 100 weeks (supplemental Fig. S2, available at www.jneurosci.org as supplemental material). There were only sparse NIIs in other brain regions. This result is consistent with our previous observations in the $\mathrm{Hdh}^{(\mathrm{CAG}) 150}$ line (Tallaksen-Greene et al., 2005). With quantitative real-time-PCR, we determined that the NR2B transgene did not affect huntingtin mRNA expression (data not shown). 
Hdh150/+;NR2B ${ }^{\text {Tg/WT }}$ double-mutant mice exhibit weight loss and motor deficits

Hdh150/+;NR2B ${ }^{\text {Tg/WT }}$ double-mutant mice exhibited an $18.4 \%$ decrease in body weight compared with other groups [Hdh150/+;NR2B ${ }^{\mathrm{Tg} / \mathrm{WT}}, \quad 29.4 \pm 3.1 \mathrm{~g}$ $($ mean $\pm \mathrm{SEM}) ; \mathrm{Hdh}+/+; \mathrm{NR} 2 \mathrm{~B}^{\mathrm{WT} / \mathrm{WT}}$, $35.7 \pm 1.4 \mathrm{~g} ; \mathrm{Hdh}+/+; \mathrm{NR} 2 \mathrm{~B}^{\mathrm{Tg} / \mathrm{WT}}$, $36.7 \pm 4.5$ g; Hdh150/+;NR2B ${ }^{\mathrm{WT} / \mathrm{WT}}$, $35.6 \pm 3.9 \mathrm{~g} ; p<0.05]$. No motor abnormalities were detected by rotarod with all groups exhibiting similar latencies to fall. Double-mutant mice exhibited significantly reduced general locomotion and exploratory behavior at 100 weeks (supplemental Fig. S3a, available at www. jneurosci.org as supplemental material) [Hdh150/+;NR2B ${ }^{\mathrm{Tg} / \mathrm{WT}}, \quad 76.8 \pm 17.7$ (mean $\pm \mathrm{SEM}$ ) crossovers $/ 2 \mathrm{~h}$; $\mathrm{Hdh}+/+$; NR2B ${ }^{\text {WT/WT }}, 251.7 \pm 30.7 ; \mathrm{Hdh}+/+$; $\mathrm{NR} 2 \mathrm{~B}^{\mathrm{Tg} / \mathrm{WT}}, 199.1 \pm 43.7$; Hdh150/+; NR2B $\left.{ }^{\text {WT/WT }}, 102.8 \pm 5.1 ; p<0.01\right]$. All groups displayed similar latencies to fall on the hanging wire test, indicating that muscle strength was not compromised and no abnormalities found with muscle histology (data not shown). Both Hdh150/ + ;NR2B ${ }^{\mathrm{Tg} / \mathrm{WT}}$ and Hdh150/+; NR2B ${ }^{\text {WT/WT }}$ require three times as long to traverse a balance beam compared with wild-type littermate controls (supplemental Fig. S3b, available at www.jneurosci.org as supplemental material) [Hdh150/+; $\mathrm{NR}_{2 \mathrm{~B}}^{\mathrm{Tg} / \mathrm{WT}}, 5.8 \pm 0.4 \mathrm{~s}($ mean $\pm \mathrm{SEM})$; Hdh150/+;NR2B WT/WT, $6.5 \pm 0.6 \mathrm{~s}$; $\mathrm{Hdh}+/+$;NR2B ${ }^{\mathrm{WT} / \mathrm{WT}}, 2.0 \pm 0.2 ; p<$ 0.05]. Footprint analysis revealed that both Hdh150/+;NR2B ${ }^{\text {Tg/WT }}$ and Hdh150/+;NR2B WT/WT display a shortening of stride length and loss of normal gait pattern compared with controls (supplemental Fig. S4, available at www. jneurosci.org as supplemental material).

\section{Discussion}

We tested the hypothesis that selective striatal degeneration observed in HD is mediated by NR2B subunits of the NMDAR in vivo. We found that double-mutant mice exhibited a significant decrease in striatal neuron number and striatal volume. The striatal degeneration observed in these mice was associated with decreases in $D_{1}$ and $D_{2}$ receptor binding and with motor deficits. These data demonstrate synergistic effects of mutant htt and overexpression of NR2B subunits with exacerbation of the HDlike phenotype characteristic of $H d h^{(\mathrm{CAG}) 150}$ mice. The NR2B transgenic line has previously been shown to exhibit increased NMDAR activation resulting in longer EPSPs and increased calcium flux (Tang et al., 1999). In situ hybridization reveals increased expression of the NR2B transgene in the cortex, striatum, hippocampus, and amygdala with little increase of expression in thalamus, brainstem, and cerebellum (Tang et al., 1999). Within areas of increased NR2B expression, the total number of NR2Bcontaining NMDARs is increased in individual synapses. NR2B
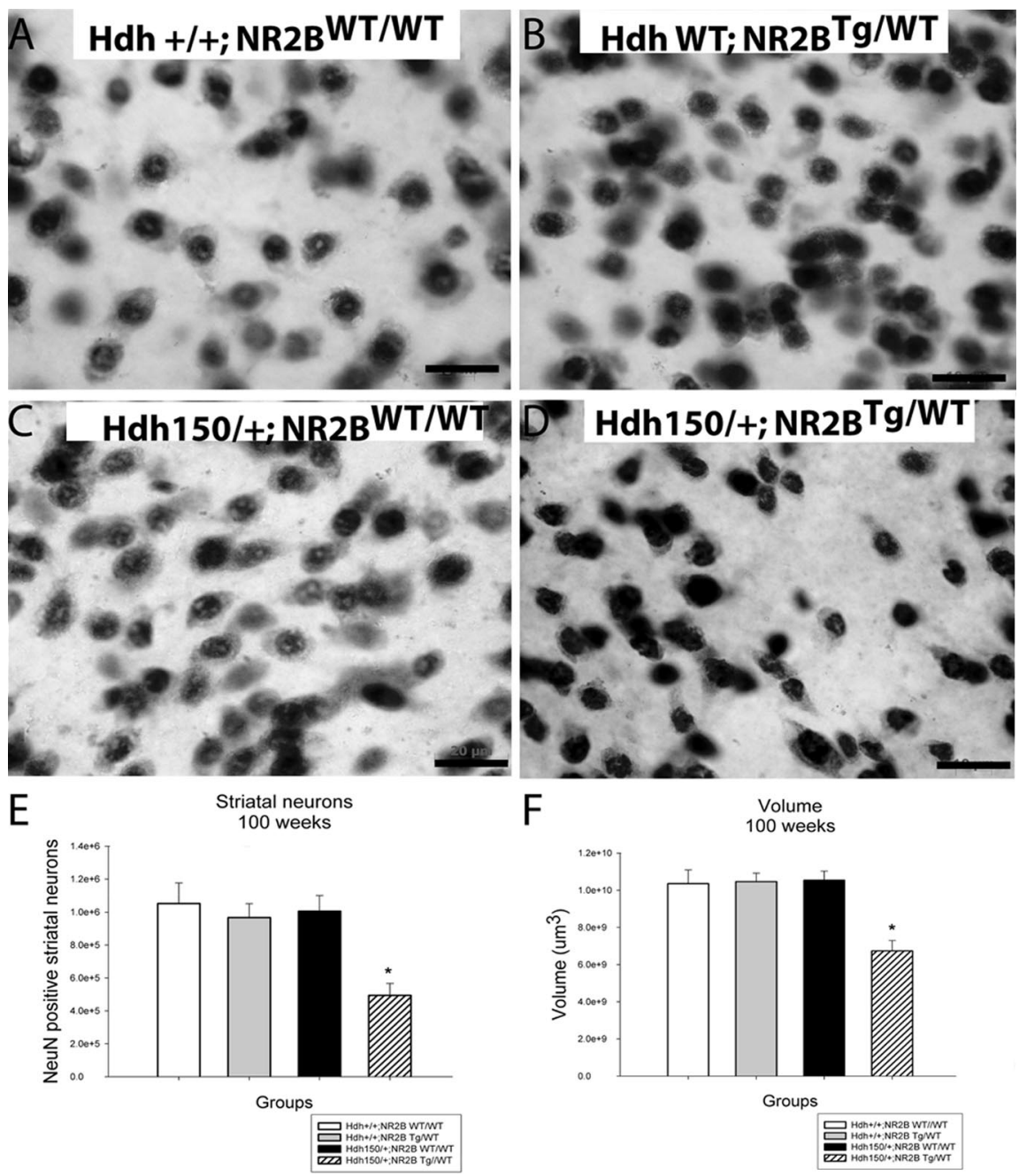

Figure 1. $\quad \mathrm{Hdh} 150 /+; \mathrm{NR} 2 \mathrm{~B}^{\mathrm{Tg} / \mathrm{WT}}$ double-mutant mice exhibit striatal neuron number and volume loss at 100 weeks. $\boldsymbol{a}-\boldsymbol{d}$, $\mathrm{Hdh} 150 /+; \mathrm{NR} 2 \mathrm{~B}^{\mathrm{Tg} / \mathrm{WT}}$ double-mutant mice display atrophic and irregular shaped NeuN-stained striatal neurons compared with $\left(\mathrm{Hdh}+/+\right.$;NR2B $^{\mathrm{WT} / \mathrm{WT}}, \mathrm{Hdh}+/+; \mathrm{NR} 2 \mathrm{~B}^{\mathrm{Tg} / \mathrm{WT}}$, and Hdh150/+ NR2B $\left.{ }^{\mathrm{WT} / \mathrm{WT}}\right){ }^{*}{ }^{*} p<0.05$. Values are expressed as mean $\pm \mathrm{SEM}$ $n=4$ animals per group; scale bar, $20 \mu \mathrm{m}$.

transgenic mice display normal growth, body weight, and survival. No anatomic abnormalities are documented in this line, and NR2B transgenic mice maintain superior performance in learning and memory tasks up to at least 20 months of age (Tang et al., 1999; Cao et al., 2007). NR2B subunit expression declines with normal aging (Magnusson et al., 2002). This is seen also in NR2B transgenic mice, but NR2B expression continues to be higher in transgenic mice than in wild-type controls (Cao et al., 2007).

Although our double-mutant mice exhibited exacerbation of striatal neuron degeneration, the time course of their disease was not altered by NR2B transgene addition. As in $H d h^{(\mathrm{CAG}) 150}$ mice, neuronal loss was a late event. Our $\mathrm{D}_{1} / \mathrm{D}_{2}$ binding data, with declines at 70 weeks, are consistent with a prolonged period of neuronal dysfunction before death of striatal neurons (Heng et al., 2007). Similar results are reported in human PET imaging studies (Weeks et al., 1996).

Rotorod performance was preserved in $\mathrm{Hdh} 150 /+$ NR2 $^{\mathrm{Tg} / \mathrm{WT}}$ mice with substantial striatal atrophy and neuronal loss. This result is consistent with our previous data in $H_{d h}^{(\mathrm{CAG}) 150}$ mice, 

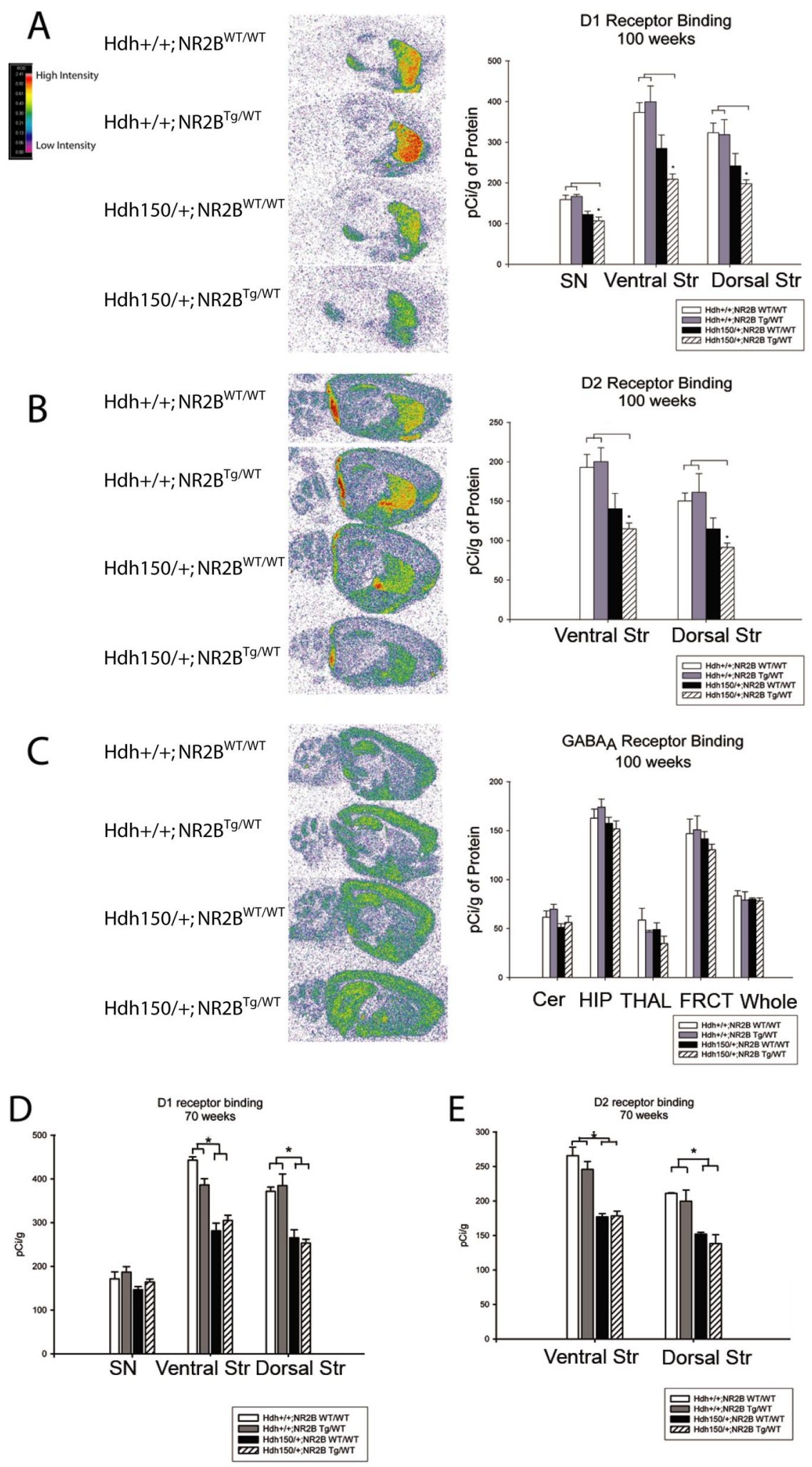

Figure 2. Hdh150/+;NR2BTg/WT double-mutant mice exhibit reductions in striatal $D_{1}$ and $D_{2}$ receptor binding, whereas Hdh150/+;NR2BWT/WT show an intermediate reduction at 100 weeks. Pseudocolor images of receptor binding. Autoradiographs were analyzed by quantitative densitometry using an MCID-M2 image analysis system. Histograms show results of densitometric analysis of film images converted to $\mathrm{pCi}$ of ${ }^{3} \mathrm{H}$-ligand bound per gram of protein. Regions analyzed are the substantia nigra (SN), ventral striatum (ventral Str), dorsal striatum (dorsal Str), whole striatum (STR), cerebellum (Cer), hippocampus (HIP), thalamus (THAL), frontal cortex (FRCT), and whole brain (Whole). $\boldsymbol{a}-\boldsymbol{c}, \mathrm{D}_{1}, \mathrm{D}_{2}$, and GABA receptor binding at 100 weeks. $\boldsymbol{d}, \boldsymbol{e}, \mathrm{D}_{1}$ and $\mathrm{D}_{2}$ receptor binding at 70 weeks. ${ }^{*} p<0.05$. Values are expressed as mean $\mathrm{pCi} / \mathrm{g} \pm$ SEM. $n=4$ animals per group. indicating that the rotorod is an insensitive measure of striatal dysfunction (Heng et al., 2007). The balance beam task and footprint analysis were more sensitive to striatal injury/dysfunction. These measures did not discriminate between Hdh150/ +;NR2 $\mathrm{B}^{\mathrm{Tg} / \mathrm{WT}}$ and Hdh150/+;NR2B ${ }^{\text {WT/WT }}$ mice. The latter did exhibit evidence of striatal neuron dysfunction as shown by diminished $D_{1} / D_{2}$ dopamine receptor binding (Fig. 2; supplemental Table 1, available at www.jneurosci.org as supplemental material). Relatively sensitive measures like the balance beam task and footprint analysis may exhibit "floor" effects that made it difficult to discriminate between Hdh150/+;NR2B ${ }^{\mathrm{Tg} / \mathrm{WT}}$ and Hdh150/ $+; \mathrm{NR} 2 \mathrm{~B}^{\mathrm{WT} / \mathrm{WT}}$ mice.

Our results are consistent with previous work in other HD murine models. Studies in transgenic mouse models of HD reveal evidence of increased NMDAR activation. Cultured striatal neurons from YAC transgenic mice expressing a fulllength human HD construct exhibit increased NMDAR activation followed by increased $\mathrm{Ca}^{2+}$ levels and mitochondrial membrane depolarization in MSNs compared with wild-type controls (Zeron et al., 2003, 2004; Shehadeh et al., 2006). Striatal neurons in these transgenic models appear more susceptible to NMDA agonist-mediated toxicity compared with wild-type mice, and NMDA induced cell death is abolished by a specific NR2B antagonist (Levine et al., 1999; Zeron et al., 2002). Consistent with these results, the R6/2 transgenic mouse model of HDexpressing exon 1 of the human HD exhibits selectively increased NMDA-evoked current and intracellular calcium (Levine et al., 1999). Recent work shows amelioration of behavioral and neuropathological deficits, and increased survival of R6/2 transgenic mice with decortication, an anti-excitotoxic intervention (Stack et al., 2007). These observations support an important role for NMDAR action, particularly the NR2B subunit, in striatal neuron degeneration in HD.

Comparative studies confirm that the pharmacological and functional properties of NMDARs depend heavily on NR2 subunit composition (Cull-Candy et al., 2001; Li et al., 2003; Loftis and Janowsky, 2003). NR2B subunit presence influences $\mathrm{Mg}^{2+}$ sensitivity and confers high $\mathrm{Ca}^{+2}$ permeability (Hollmann and Heinemann, 1994). NMDAR activation may either promote neuronal survival or cause excitotoxic injury (Papadia and Hardingham, 2007). In some model systems, NR2Bcontaining NMDARs promote prodeath 
signaling, whereas NR2A-containing NMDARs promote survival (Liu et al., 2007). Considerable other work suggests that NMDAR localization is the salient factor with extrasynaptic NMDARs promoting neuronal death, and synaptic NMDARs promote survival (Hardingham et al., 2002; Léveillé et al., 2008; Papadia et al., 2008; Martel et al., 2009). In mature mammalian neurons, however, NR2B subunit containing NMDARs tend to be preferentially localized extrasynaptically (Tovar and Westbrook, 1999). NR2B subunit containing NMDARs are highly expressed by MSNs (Monyer et al., 1992). In vitro coexpression studies of NMDARs and htt in non-neuronal cells indicate sensitization of NR2B function by mutant htt (Chen et al., 1999; Zeron et al., 2001).

Recent in vitro work directly links sensitization of NMDARNR2B dysfunction mediated by mutant htt to deranged intracellular $\mathrm{Ca}^{2+}$ homeostasis and apoptosis in HD (Bezprozvanny and Hayden, 2004; Fan and Raymond, 2007). Coexpression of NMDARs with expanded polyglutamine htt in non-neuronalcultured cells enhances excitotoxic cell death, an effect maximized by NR2B subunit expression (Zeron et al., 2001; Li et al., 2004). Similarly, cultured MSNs from a mouse model of HD exhibit increased glutamate-evoked peak currents and enhanced $\mathrm{Ca}^{2+}$ levels mediated by the NR2B subunit (Zeron et al., 2002, 2004; Shehadeh et al., 2006). These findings support the hypothesis that mutant htt enhances neuronal susceptibility to NMDAR-mediated excitotoxic insult, particularly in neurons expressing NR2B-containing NMDARs (Cepeda et al., 2001; Zeron et al., 2002; Li et al., 2003; Tang et al., 2003).

Other mechanistic hypotheses of HD pathogenesis have been suggested, such as transcriptional dysregulation, mitochondrial dysfunction, axonal transport defects, brain-derived neurotropic factor depletion, and proteosomal dysfunction. All these hypotheses have some support (Imarisio et al., 2007). It is possible that expanded polyQ htt is neurotoxic because it has multiple deleterious effects (Aronin et al., 1999). Our results support NMDAR excitotoxicity as a proximate cause of neurodegeneration in HD, but there may be an overlapping network of expanded polyQ effects causing neurodegeneration. Although our double mutants exhibit exacerbation of the phenotype, they do not show any apparent change in the time course of the phenotype and exhibit similar pathological and behavioral changes to $H d h^{(\mathrm{CAG}) 150}$ mice up to 70 weeks. In other murine genetic models, enhanced NMDAR $\mathrm{Ca}^{2+}$ currents are found in embryonic neurons, suggesting that pathologic dysregulation of NMDAR signaling is an early event in HD (Zeron et al., 2004). It is plausible that later occurring, pathologic effects of expanded polyQ htt could interact with the potentiation of NR2B-NMDAR signaling in synergistic or additive manner to produce neurodegeneration. Our in vivo findings are consistent with previous reports that subunitspecific interactions between NR2B-containing NMDARs and expanded mutant htt potentiate NMDAR-initiated neuronal death and are important mediators of neurodegeneration in HD. NMDAR antagonists are viable candidates as interventions in $\mathrm{HD}$, but it seems likely that highly selective NR2B antagonists will be required.

\section{References}

Aronin N, Kim M, Laforet G, DiFiglia M (1999) Are there multiple pathways in the pathogenesis of Huntington's disease? Philos Trans R Soc Lond B Biol Sci 354:995-1003.

Bazzett TJ, Becker JB, Kaatz KW, Albin RL (1993) Chronic intrastriatal dialytic administration of quinolinic acid produces selective neural degeneration. Exp Neurol 120:177-185.

Beal MF, Kowall NW, Ellison DW, Mazurek MF, Swartz KJ, Martin JB (1986)
Replication of the neurochemical characteristics of Huntington's disease by quinolinic acid. Nature 321:168-171.

Bezprozvanny I, Hayden MR (2004) Deranged neuronal calcium signaling and Huntington disease. Biochem Biophys Res Commun 322:1310-1317.

Brouillet E, Hantraye P, Ferrante RJ, Dolan R, Leroy-Willig A, Kowall NW, Beal MF (1995) Chronic mitochondrial energy impairment produces selective striatal degeneration and abnormal choreiform. Proc Natl Acad Sci U S A 92:7105-7109.

Cao X, Cui Z, Feng R, Tang YP, Qin Z, Mei B, Tsien JZ (2007) Maintenance of superior learning and memory function in NR2B transgenic mice during aging. Eur J Neurosci 25:1815-1822.

Cepeda C, Ariano MA, Calvert CR, Flores-Hernández J, Chandler SH, Leavitt BR, Hayden MR, Levine MS (2001) NMDA receptor function in mouse models of Huntington disease. J Neurosci Res 66:525-539.

Chen N, Luo T, Wellington C, Metzler M, McCutcheon K, Hayden MR, Raymond LA (1999) Subtype-specific enhancement of NMDA receptor currents by mutant huntingtin. J Neurochem 72:1890-1898.

Coyle JT, Schwarcz R (1976) Lesion of striatal neurones with kainic acid provides a model for Huntington's chorea. Nature 263:244-246.

Cull-Candy S, Brickley S, Farrant M (2001) NMDA receptor subunits: diversity, development and disease. Curr Opin Neurobiol 11:327-335.

Dingledine R, Borges K, Bowie D, Traynelis SF (1999) The glutamate receptor ion channels. Pharmacol Rev 51:7-61.

Fan MM, Raymond LA (2007) N-methyl-D-aspartate (NMDA) receptor function and excitotoxicity in Huntington's disease. Prog Neurobiol 81:272-293.

Ferrante RJ, Kowall NW, Cipolloni PB, Storey E, Beal MF (1993) Excitotoxin lesions in primates as a model for Huntington's disease: histopathologic and neurochemical characterization. Exp Neurol 119:46-71.

Greene JG, Greenamyre JT (1995) Characterization of the excitotoxic potential of the reversible succinate dehydrogenase inhibitor malonate. J Neurochem 64:430-436.

Hardingham GE, Fukunaga Y, Bading H (2002) Extrasynaptic NMDARs oppose synaptic NMDARs by triggering CREB shut-off and cell death pathways. Nat Neurosci 5:405-414.

Heng MY, Tallaksen-Greene SJ, Detloff PJ, Albin RL (2007) Longitudinal evaluation of the Hdh(CAG)150 knock-in murine model of Huntington's disease. J Neurosci 27:8989-8998.

Hollmann M, Heinemann S (1994) Cloned glutamate receptors. Annu Rev Neurosci 17:31-108.

Imarisio S, Carmichael J, Korolchuk V, Chen CW, Saiki S, Rose C, Krishna G, Davies JE, Ttofi E, Underwood BR, Rubinsztein DC (2007) Huntington's disease: from pathology and genetics to potential therapies. Biochem J 412:199-209.

Léveillé F, El Gaamouch F, Gouix E, Lecocq M, Lobner D, Nicole O, Buisson A (2008) Neuronal viability is controlled by a functional relation between synaptic and extrasynaptic NMDA receptors. FASEB J 22:4258-4271.

Levine MS, Klapstein GJ, Koppel A, Gruen E, Cepeda C, Vargas ME, Jokel ES, Carpenter EM, Zanjani H, Hurst RS, Efstratiadis A, Zeitlin S, Chesselet MF (1999) Enhanced sensitivity to N-methyl-D-aspartate receptor activation in transgenic and knockin mouse models of Huntington's disease. J Neurosci Res 58:515-532.

Li L, Fan M, Icton CD, Chen N, Leavitt BR, Hayden MR, Murphy TH, Raymond LA (2003) Role of NR2B-type NMDA receptors in selective neurodegeneration in Huntington disease. Neurobiol Aging 24:1113-1121.

Li L, Murphy TH, Hayden MR, Raymond LA (2004) Enhanced striatal NR2B-containing N-methyl-D-aspartate receptor-mediated synaptic currents in a mouse model of Huntington's disease. J Neurophysiol 92:2738-2746.

Liu Y, Wong TP, Aarts M, Rooyakkers A, Liu L, Lai TW, Wu DC, Lu J, Tymianski M, Craig AM, Wang YT (2007) NMDA receptor subunits have differential roles in mediating excitotoxic neuronal death both in vitro and in vivo. J Neurosci 27:2846-2857.

Loftis JM, Janowsky A (2003) The N-methyl-D-aspartate receptor subunit NR2B: localization, functional properties, regulation, and clinical implications. Pharmacol Ther 97:55-85.

Magnusson KR, Nelson SE, Young AB (2002) Age-related changes in the protein expression of subunits of the NMDA receptor. Mol Brain Res 99:40-45.

Martel MA, Wyllie DJ, Hardingham GE (2009) In developing hippocampal neurons, NR2B-containing N-methyl-d-aspartate receptors (NMDARs) 
can mediate signaling to neuronal survival and synaptic potentiation, as well as neuronal death. Neuroscience 158:334-343.

McGeer EG, McGeer PL (1976) Duplication of biochemical changes of Huntington's chorea by intrastriatal injections of glutamic and kainic acids. Nature 263:517-519.

Monyer H, Sprengel R, Schoepfer R, Herb A, Higuchi M, Lomeli H, Burnashev N, Sakmann B, Seeburg PH (1992) Heteromeric NMDA receptors: molecular and functional distinction of subtypes. Science 256:1217-1221.

Papadia S, Hardingham GE (2007) The dichotomy of NMDA receptor signaling. Neuroscientist 13:572-579.

Papadia S, Soriano FX, Léveillé F, Martel MA, Dakin KA, Hansen HH, Kaindl A, Sifringer M, Fowler J, Stefovska V, McKenzie G, Craigon M, Corriveau R, Ghazal P, Horsburgh K, Yankner BA, Wyllie DJ, Ikonomidou C, Hardingham GE (2008) Synaptic NMDA receptor activity boosts intrinsic antioxidant defenses. Nat Neurosci 11:476-487.

Schwarcz R, Whetsell WO Jr, Mangano RM (1983) Quinolinic acid: an endogenous metabolite that produces axon-sparing lesions in rat brain. Science 219:316-318.

Shehadeh J, Fernandes HB, Zeron Mullins MM, Graham RK, Leavitt BR, Hayden MR, Raymond LA (2006) Striatal neuronal apoptosis is preferentially enhanced by NMDA receptor activation in YAC transgenic mouse model of Huntington disease. Neurobiol Dis 21:392-403.

Stack EC, Dedeoglu A, Smith KM, Cormier K, Kubilus JK, Bogdanov M, Matson WR, Yang L, Jenkins BG, Luthi-Carter R, Kowall NW, Hersch SM, Beal MF, Ferrante RJ (2007) Neuroprotective effects of synaptic modulation in Huntington's disease R6/2 mice. J Neurosci 27:12908-12915.

Tallaksen-Greene SJ, Crouse AB, Hunter JM, Detloff PJ, Albin RL (2005) Neuronal intranuclear inclusions and neuropil aggregates in $H d h^{C A G(150)}$ knockin mice. Neuroscience 131:843-852.
Tang TS, Tu H, Chan EY, Maximov A, Wang Z, Wellington CL, Hayden MR, Bezprozvanny I (2003) Huntingtin and huntingtin-associated protein 1 influences neuronal calcium signaling mediated by inositol- $(1,4,5)$ triphosphate receptor type 1. Neuron 39:227-239.

Tang YP, Shimizu E, Dube GR, Rampon C, Kerchner GA, Zhuo M, Liu G, Tsien JZ (1999) Genetic enhancement of learning and memory in mice. Nature 401:63-69.

Tovar KR, Westbrook GL (1999) The incorporation of NMDA receptors with a distinct subunit composition at nascent hippocampal synapses in vitro. J Neurosci 19:4180-4188.

Waxman EA, Lynch DR (2005) N-methyl-D-aspartate receptor subtypes: multiple roles in excitotoxicity and neurological disease. Neuroscientist 11:37-49.

Weeks RA, Piccini P, Harding AE, Brooks DJ (1996) Striatal D1 and D2 dopamine receptor loss in asymptomatic mutation carriers of Huntington's disease. Ann Neurol 40:49-54.

Zeron MM, Chen N, Moshaver A, Lee AT, Wellington CL, Hayden MR, Raymond LA (2001) Mutant huntingtin enhances excitotoxic cell death. Mol Cell Neurosci 17:41-53.

Zeron MM, Hansson O, Chen N, Wellington CL, Leavitt BR, Brundin P, Hayden MR, Raymond LA (2002) Increased sensitivity to N-methyl-Daspartate receptor-mediated excitotoxicity in a mouse model of Huntington's disease. Neuron 33:849-860.

Zeron MM, Fernandes HB, Krebs C, Shehadeh J, Wellington CL, Leavitt BR, Baimbridge KG, Hayden MR, Raymond LA (2004) Potentiation of NMDA receptor-mediated excitotoxicity linked with intrinsic apoptotic pathway in YAC transgenic mouse model of Huntington's disease. Mol Cell Neurosci 25:469-479. 